\title{
Pengelompokkan Mahasiswa Akademik Keperwatan Berdasarkan Asal Sekolah dan Nilai Akademik Menggunakan Metode Clustering K-Means
}

\author{
Lisna Zahrotun ${ }^{1, *}$, Yunus Fajri ${ }^{1}$, Anna Hendri Soleliza Jones ${ }^{1}$, Eni Purwaningsih ${ }^{2}$ \\ ${ }^{1}$ Teknik Informatika, Fakultas Teknologi Industri, Universitas Ahmad Dahlan, Yogyakarta, Indonesia \\ 2 Akademi Perawatan Karya Bakti Husada, Yogyakarta, Indonesia \\ Email: 1,"Lisna.zahrotun@tif.uad.ac.id, ${ }^{2}$ yunusf42@gmail.com, ${ }^{3}$ annahendri@tif.uad.ac.id, ${ }^{4}$ enipurwaningsih1905@gmail.com \\ Email Penulis Korespondensi: Lisna.zahrotun@tif.uad.ac.id \\ Submitted: 21/12/2021; Accepted: 29/12/2021; Published: 31/12/2021
}

\begin{abstract}
Abstrak-Akademik Keperawatan Karya Bakti Husada (AKPER KBH) Bantul merupakan salah satu akademik yang membuka jurusan keperawatan. Berdasarkna wawancara dengan Direktur AKPER KBH syarat pendaftaran menjadi mahasiswa keperawatan saat ini adalah siswa lulusan dari semua jurusan dan semua sekolah menengah. AKPER KBH belum pernah melakukan analisa terhadap data mahasiswa apakah ada hubungan antara riwayat pada waktu sekolah menengah dengan nilai kelulusan IPK sebagai bahan evaluasi dalam proses pembelajaran, meskipun untuk saat ini dengan variasinya mahasiswa baru menyebabkan tingkat kesulitan dalam proses pembelajaran lebih sulit dibandingkan dengan sebelumnya, sedangkan capaian IPK sangat penting dalam pencarian pekerjaan setelah lulus nanti. Tujuan dari penelitian ini adalah mengelompokkan data akademik mahasiswa AKPER data mahasiswa berdasarkan data asal sekolah, nilai IPK, dan nilai Keperawatan Medical Bedah II (KMB II), Keperawatan Jiwa II (Kep Jiwa II), Keperawatan Anak II (Kep Anak II), Keperawatan Maternitas II (Kep Maternitas II), dan Keperawatan Medical Bedah (KMB V). Tahapan dalam penelitian ini meliputi pengambilan data, pembersihan data, seleksi data, transformasi data, pengelompokan data menggunakan metode K-Means dan representasi pengetahuan, pengujian yang digunakan dalam penelitian ini adalah purity tes. Dari percobaan yang dilakukan nilai akurasi tertinggi yaitu 0.924 dengan jumlah cluster 3 .
\end{abstract}

Kata kunci: Data Mining; Clustering; K-Means

Abstract-Nursing Academic of Karya Bakti Husada (AKPER KBH) Bantul is one of the academics that opened the 2000 department. Based on an interview with the Director of AKPER KBH, the registration requirements to become a student of the Academy are currently graduates from all majors and all high schools. AKPER KBH has not analyzed student data whether there is a relationship between high school history and passing grades of GPA as an evaluation material in the learning process, although at this time with the variation of new students causing difficulty in learning difficult compared to before, while GPA achievement is very important in finding job after graduation. The purpose of this study is to classify academic data of AKPER students based on data on school origin, GPA scores, and Medical Surgical Nursing II (KMB II), Mental Nursing II (Kep Jiwa II), Child Nursing II (Kep Anak II), Maternity Nursing II (Kep Maternitas II), and Medical Surgical Nursing ( KMB V). The stages in this study include data collection, data search, data selection, data transformation, data grouping using the K-Means method and knowledge representation, the test used in this study is the purity test. From the experiments conducted, the accuracy value is 0.924 with the number of clusters 3 .

Keywords: Data Mining; Clustering; K-Means

\section{PENDAHULUAN}

Pendidikan tenaga medis di Indonesia merupakan salah satu pendidikan yang memiliki banyak peminat, diantaranya jurusan keperawatan. Banyak sekolah-sekolah keperawatan yang ada di Indonesia baik yang tergabung dalam Politeknik maupun Universitas. Secara umum syarat untuk dapat memasuki sekolah keperawatan ini adalah lulusan IPA baik dari sekolah SMA/MA, tinggi badan dan kesehatan jasmani dan rokhani. Selama 1 tahun terakhir di seluruh dunia mengalami wabah covid-19 tidak terkecuali Indonesia. Keadaan ini menyebabkan kebutuhan tenaga medis semakin banyak. Salah satu tenaga medis yang dibutuhkan adalah perawat, karena perawat merupakan bagian garda depan dalam penanganan pasien covid-19. Salah satu persyaratan untuk dapat mengabdikan menjadi tenaga medis sebagai perawat adalah Indek Prestasi Kumulatif (IPK).

Akademik Keperawatan Karya Bakti Husada (AKPER KBH) Bantul merupakan salah satu akademik yang membuka jurusan keperawatan. Berdasarkan wawancara dengan Direktur AKPER KBH syarat pendaftaran menjadi mahasiswa keperawatan saat ini adalah siswa lulusan dari semua jurusan dan semua sekolah menengah. AKPER KBH belum pernah melakukan analisa terhadap data mahasiswa apakah ada hubungan antara riwayat pada waktu sekolah menengah dengan nilai kelulusan IPK sebagai bahan evaluasi dalam proses pembelajaran, meskipun untuk saat ini dengan variasinya mahasiswa baru menyebabkan tingkat kesulitan dalam proses pembelajaran lebih sulit dibandingkan dengan sebelumnya, sedangkan capaian IPK sangat penting dalam pencarian pekerjaan setelah lulus nanti.

Salah satu bidang yang digunakan dalam penggalian data adalah data mining. Diantara beberapa teknik yang ada dalam data mining ini adalah Teknik data mining yang lain adalah pengelompokkan, dimana dalam pengelompokkan ini digunakan untuk mencari kelompok data yang memiliki karakteristik tertentu. Pengelompokkan karakteristik data rumah tangga [1], pemetaan kualifikasi pendidikan di Indonesia [2], pengelompokkan karakteristik pelanggan telepon [3] dan pengelompokkan dokumen berbasis teks [4]. Penelitian sebelumnya adalah analisis dua metode dimana hasil pengelompokkan dengan metode $K$-means lebih baik dari pengelompokkan menggunakan metode Agglomerative Hierarchichal Clustering (AHC). Analisis ini dilakukan pada pengelompokkan data 
Building of Informatics, Technology and Science (BITS)

Volume 3, No 3, Desember 2021 Page: 369-374

ISSN 2684-8910 (media cetak)

ISSN 2685-3310 (media online)

DOI 10.47065/bits.v3i3.1110

penumpang bus trans jogja [5]. Metode K-Means juga efektif dan efisien dalam mengelompokkan dalam mengelompokkan data berbentuk text [4].

Penelitian tentang pengelompokkan data riwayat mahasiswa sebelum kuliah dan masa studi juga pernah dilakukan sebelumnya dengan menggunakan metode K-Medoids [6] dan Aglomerafit Hierarchical Clustering (AHC) [7].

Dengan adanya teknik-teknik data mining dalam penggalian data, maka dalam penelitian ini akan dilakukan analisis data mahasiswa AKPER KBH dengan melakukan pengelompokkan data akademik mahasiswa dan mencari pola asosiasi antara variable data sebelum kuliah dan nilai IPK. Tujuan penelitian yang dilakukan ini adalah mendapatkan hubungan asosiasi antara variable data mahasiswa berdasarkan proses pengelompokkan sebelumnya. Hasil analisis ini siharapkan mampu memberikan rekomendasi terhadap syarat penerimaan mahasiswa baru pada AKPER KBH di tahun-tahun berikutnya.

\section{METODOLOGI PENELITIAN}

\subsection{Tahapan Penelitian}

Tahap proses penelitian merupakan tahap awal dan sangat penting karena kesalahan ditahap ini akan menyebabkan kesalahan-kesalahan ditahap selanjutnya. Tahapan proses penelitian ditunjukkan dalam Gambar 1.

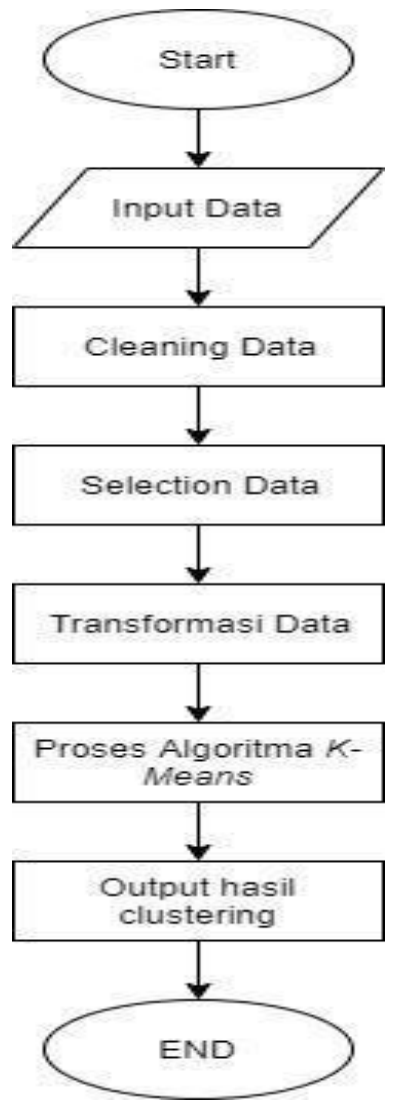

Gambar 1. Tahap Penelitian

1. Input Data

Tahapan yang pertama adalah tahapan input data, tahap input data yaitu menginputkan data yang sudah diperoleh sebelumnya, yaitu data mahasiswa AKPER KBH.

2. Cleaning Data

Cleaning data atau pembersihan data merupakan proses dimana data mahasiswa yang tidak lengkap akan di hapus.

3. Selection Data

Selection data atau seleksi data merupakan tahapan yang memutuskan atribut-atribut yang akan digunakan dalam penelitian ini.

4. Transformasi Data

Transformasi data adalah tahapan dimana data diubah menjadi nilai yang memiliki format tertentu. Pada tahapan ini, data yang berbentuk alphabet akan diubah menjadi data numeric (angka) dan data kategorikan diubah dalam teknik One Hot Encoding.

5. Proses Algoritma K-Means 
Tahapan ini merupakan tahapan yang amat penting, dikarenakan algoritma K-Means mengolah data yang nantinya akan diterapkan kedalam sistem. Clustering merupakan salah satu teknik dalam data mining. Dimana data mining merupakan proses agar mendapatkan sutau pola atau pengetahuan yang bermanfaat dari sebuah data yang besar [8]. K-Means clustering adalah salah satu metode pengelompokan yang begitu populer dan banyak digunakan dikarenakan kecepatan dalam pengklasterannya. K-Means termasuk dalam pengelompokan data nonhirarki (sekatan) yang berusaha membagi data kedalam dua atau lebih cluster. Metode $K$-Means membagi data menjadi beberapa cluster, sehingga data mempunyai karakteristik atau ciri khas yang sama maka akan dimasukan kedalam satu kelompok yang mempunyai ciri khas sama, jika data memiliki ciri khas yang berbeda atau lain akan dijadikan satu kedalam kelompok dengan ciri khas yang lain. Clustering menggunakan metode $K$-Means mempunyai beberapa tahapan, menurut [9] yaitu:

a. Menentukan nilai k, nilai k merupakan jumlah cluster yang akan dibentuk (jumlah cluster harus lebih kecil dari jumlah data).

b. Menginisialisasi k yang akan digunakan sebagai centroid yang nantinya akan dibangkitan secara acak.

c. Menggunakan persamaan Euclidean Distance untuk menghitung jarak dari setiap data terhadap masingmasing centroid, persamaan Euclidean Distance:

$d(P, C)=\sqrt{\sum_{i=1}^{n}\left(P_{i}-C_{i}\right)^{2}}$

Keterangan:

$\mathrm{N}$ : Jumlah Data

$\mathrm{P}:$ Data

$\mathrm{C}:$ Centroid

I : Iterasi

d. Mengelompokan setiap data berdasarkan jarak yang paling dekat, yaitu antara data dengan centroid.

e. Menentukan posisi centroid baru (k).

f. Jika centroid yang baru dengan centroid yang lama sama, maka proses clustering dihentikan. Bila masih terdapat perubahan nilai centroid yang baru dengan yang lama, maka Kembali pada Langkah ke 3 .

6. Output hasil clustering atau representase pengetahuan

Dalam tahap ini merupakan analisis hasil pengelompokkan yang akan menjadi rekomendasi bagi pihak AKPER $\mathrm{KBH}$

\section{HASIL DAN PEMBAHASAN}

Dataset Mahasiswa AKPER KBH memiliki jumlah data sebanyak 386 data mahasiswa dengan atribut NIM, Nama Mahasiswa, Tanggal Lulus, Asal Sekolah, Nilai IPK, Keperawatan Medical Bedah II (KMB II), Keperawatan Jiwa II (Kep Jiwa II), Keperawatan Anak II (Kep Anak II), Keperawatan Maternitas II (Kep Maternitas II), dan Keperawatan Medical Bedah (KMB V). Pada penelitian ini, data yang akan diolah dapat dilihat pada gambar 1.

\begin{tabular}{|c|c|c|c|c|c|c|c|c|c|c|}
\hline No & $\mathrm{Nim}$ & Nama Mahasiswa & Tanggal Lulus & Asal Sekolah & Nilai IPK & KMB II & Kep Jiwa ll & Kep Anak II & Kep Maternitas II & KMB IV \\
\hline 1 & 1510680.0 & Ety Rita Astuti & $2009-08-1100.00 .00$ & $\mathrm{NaN}$ & 280 & $\mathrm{NaN}$ & $\mathrm{NaN}$ & $\mathrm{NaN}$ & $\mathrm{NaN}$ & $\mathrm{NaN}$ \\
\hline 2 & 1610715.0 & Agus Rina Tri Ariyani & $2009-08-1100: 00-00$ & $\mathrm{NaN}$ & 2.80 & $\mathrm{NaN}$ & $\mathrm{NaN}$ & $\mathrm{NaN}$ & $\mathrm{NaN}$ & $\mathrm{NaN}$ \\
\hline 3 & 1610716.0 & Ahmad Lutf Harin & $2009-08-1100 \cdot 0000$ & NaN & 260 & $\mathrm{NaN}$ & NaN & $\mathrm{NaN}$ & NaN & $\mathrm{NaN}$ \\
\hline 4 & 1610717.0 & Andarini Anggi Kisworowats Udit & $2009-08-1100 \cdot 00.00$ & NaN & 2.70 & $\mathrm{NaN}$ & $\mathrm{NaN}$ & $\mathrm{NaN}$ & NaN & $\mathrm{NaN}$ \\
\hline 5 & 1610718.0 & Dedi lka Prasetya & $2009-08-1100: 00.00$ & NaN & 3.40 & NaN & $\mathrm{NaN}$ & $\mathrm{NaN}$ & NaN & $\mathrm{NaN}$ \\
\hline$\ldots$ & $\cdots$ & & & & & $\ldots$ & & & - & \\
\hline 382 & 20161261.0 & Kristiana & 2019 & SMKS & 3.16 & B & B & $B$ & A & A \\
\hline 383 & 201612620 & Nur Eka Kumiawan & 2019 & SMAN & 304 & B & B & B & A & B \\
\hline 384 & 201612630 & Septiningrum Nur Catyati & 2019 & SMAS & 262 & B & B & B & A & B \\
\hline 385 & 201612640 & Trisna Nurhakm & 2019 & Paket C & 3.57 & B & B & B & A & A \\
\hline 396 & 20161265.0 & Ulfah Nur 'Aini & 2019 & MAN & 3.29 & B & B & B & A & A \\
\hline
\end{tabular}

Gambar 2. Tabel Data Mahasiswa AKPER KBH

Dari data mentah tersebut, kemudian melakukan proses preprocessing. Preprocessing merupakan tahapan pembersihan data. Data yang tidak konsisten, noise dan atribut yang tidak digunakan akan dihapus. Dari 306 data setelah dilakukan prose spembersihan data hanya menjadi 218 data yang siap untuk dilakukan proses pengelompokkan. SEdangakn untuk proses seleksi data 
Building of Informatics, Technology and Science (BITS)

Volume 3, No 3, Desember 2021 Page: 369-374

ISSN 2684-8910 (media cetak)

ISSN 2685-3310 (media online)

DOI 10.47065/bits.v3i3.1110

Dari banyaknya atribut, hanya beberapa atribut saja yang akan digunakan, diantaranya adalah Asal Sekolah, Nilai IPK, KMB 2, Kep Jiwa 2, Kep Anak 2, Kep Maternitas 2, dan KMB 4. Preprocessing dapat dilihat pada gambar 3 berikut:

\begin{tabular}{rrrrrrrr}
\hline & Asal_Sekolah & Ipk & KMB II & Kep Jiwa II & Kep Anak II & Kep Maternitas II & KMB IV \\
\hline $\mathbf{0}$ & SMAN & 2.80 & B & B & B & B & B \\
1 & SMAN & 3.29 & B & B & B & B & B \\
2 & SMAN & 2.83 & B & B & B & B & B \\
3 & SMAN & 2.98 & B & B & B & B & B \\
$\mathbf{4}$ & SMAN & 2.97 & B & B & B & B & B \\
$\ldots$ & & & $\ldots$ & $\ldots$ & $\ldots$ & A & A \\
214 & SMKS & 3.16 & B & B & B & A & B \\
$\mathbf{2 1 5}$ & SMAN & 3.04 & B & B & B & A & B \\
$\mathbf{2 1 6}$ & SMAS & 2.62 & B & B & B & A & A \\
$\mathbf{2 1 7}$ & Paket C & 3.57 & B & B & B & A & A \\
$\mathbf{2 1 8}$ & MAN & 3.29 & B & B & B & &
\end{tabular}

Gambar 3. Tabel hasil dari pembersihan dan seleksi data

Tahapan selanjutnya adalah transformasi data. Data yang akan di transformasi adalah atribut KMB 2, Kep Jiwa 2, Kep Anak 2, Kep Maternitas 2, KMB 4 dan atribut Asal Sekolah yang akan di transformasi menggunakan metode One Hot Encoding. Nilai Matakuliah di transformasi dari nilai alphabet menjadi nilai numeric dengan ketentuan nilai A menjadi 4, B menjadi 3, C menjadi 2, D menjadi 1, dan E menjadi 0. Hasil dari transformasi data dapat dilihat pada gambar 4.

\begin{tabular}{|c|c|c|c|c|c|c|c|c|c|c|c|}
\hline & Asi_tstholah & lpti & Fiil & Kepdina & Kep Anak & Kep butemilas & $\begin{aligned} \text { kovili } \\
\text { N }\end{aligned}$ & MA & MAK & MAN & Prisen \\
\hline 0 & $5 M N$ & 20 & 3 & 3 & 3 & $j$ & 3 & $\theta$ & 0 & 0 & q \\
\hline 1 & GMA & 32 & 3 & 3 & 3 & 3 & 3 & 6 & 0 & 0 & 0 \\
\hline 2 & SMN & 203 & 3 & 3 & 3 & 3 & 3 & 0 & 0 & 0 & a \\
\hline 3 & SMN & $2 \mathrm{~Pa}$ & 3 & 3 & 3 & 3 & 3 & 9 & 0 & D & a \\
\hline 4 & SMN & $2 n$ & j & 3 & 3 & j & 3 & $\theta$ & 0 & 0 & 0 \\
\hline$=$ & & & & & & & & & & & \\
\hline 314 & suxs & 310 & j & 1 & 3 & 4 & 4 & $\theta$ & 6 & 0 & 0 \\
\hline 215 & SMN & 304 & 3 & 3 & 3 & 4 & 3 & $\theta$ & 0 & 0 & 0 \\
\hline 216 & SMRS & 26 & 3 & 3 & 3 & 4 & 3 & $\theta$ & 0 & 0 & a \\
\hline 217 & Pabs 6 & 357 & 3 & 3 & 3 & 4 & 4 & $\theta$ & 0 & 0 & q \\
\hline 218 & MN & 32 & 3 & 3 & 3 & 4 & 4 & 0 & 0 & 1 & 0 \\
\hline
\end{tabular}

Gambar 4. Tabel hasil transformasi data

Setelah mendapatkan hasil dari transformasi data, tahap selanjutnya adalah penerapan Algoritma $K$-Means. Langkah awal algoritma $K$-Means adalah menentukan nilai k dimana nilai k merupakan jumlah cluster yang akan dibentuk. Nilai k yang digunakan adalah 2, 3, 4, 5. Setelah mempunyai hasil clustering dari k: 2, 3, 4, dan 5 dilakukan pengujian clustering menggunakan metode purity untuk mendapatkan jumlah cluster yang paling cocok. Hasil dari pengujian purity setiap k dapat dilihat pada Tabel 1 dan Gambar grafik hasil akurasi ditunjukkan dalam Gambar 2.

Tabel 1. Hasil Pengujian Purity

\begin{tabular}{cc}
\hline Nilai K (Jumlah Cluster) & Hasil Purity \\
\hline 2 & 0.93 \\
3 & 0.924 \\
4 & 0.893 \\
5 & 0.75 \\
\hline
\end{tabular}




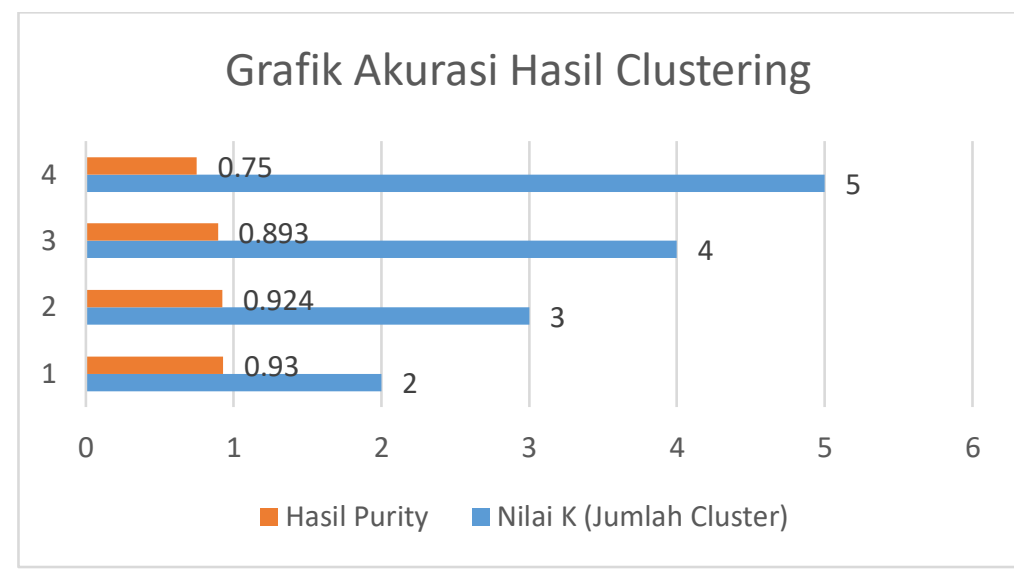

Gambar 5. Grafik pengujian hasil clustering

Dari hasil perhitungan tersebut didapatkan hasil 3 pusat cluster, dimana titik pusat cluster pertama dapat dilihat pada Gambar 3 .
$2.05128205 e-01$
$3.84615385 \mathrm{e}-02$
$6.41025641 \mathrm{e}-02$
$2.82051282 \mathrm{e}-01$
$6.47435897 \mathrm{e}-01$
$2.56410256 \mathrm{e}-02$
$1.28205128 \mathrm{e}-02$
$2.17948718 \mathrm{e}-01$
$1.28205128 \mathrm{e}-02$
$5.12820513 e-02$
$1.28205128 \mathrm{e}-02$
$6.66133815 \mathrm{e}-16$
$2.43589744 e-01$
$1.92307692 \mathrm{e}-01$
$2.17948718 \mathrm{e}-01$
1. $28205128 \mathrm{e}-02$

Gambar 6. Titik Pusat Cluster 1

Sedangkan untuk titik pusat cluster kedua dapat dilihat pada Gambar 4.
$1.75824176 \mathrm{e}-01$
$2.19780220 \mathrm{e}-02$
$0.00000000 \mathrm{e}+00$
$3.73626374 \mathrm{e}-01$
$5.93406593 e-01$
$0.00000000 \mathrm{e}+00$
$0.00000000 \mathrm{e}+00$
$1.52655666 \mathrm{e}-16$
$0.00000000 \mathrm{e}+00$
$0.00000000 \mathrm{e}+00$
$0.00000000 \mathrm{e}+00$
$1.00000000 \mathrm{e}+00$
$-4.16333634 \mathrm{e}-17$
$00000000 \mathrm{e}+00$
$1.38777878 \mathrm{e}-16$
$0.00000000 \mathrm{e}+00$

Gambar 7. Titik Pusat Cluster 2

Titik pusat cluster ketiga dapat dilihat pada Gambar 5.
$7.60000000 \mathrm{e}-01$
$8.30000000 \mathrm{e}-01$
$0.00000000 \mathrm{e}+00$
$4.00000000 \mathrm{e}-02$

$8.60000000 \mathrm{e}-01$

$0.00000000 \mathrm{e}+00$

$8.20000000 \mathrm{e}-01$

$0.00000000 \mathrm{e}+00$

$0.00000000 \mathrm{e}+00$

$1.60000000 \mathrm{e}-01$
$0.00000000 \mathrm{e}+00$

$1.60000000 \mathrm{e}-01$
$3.80000000 \mathrm{e}-01$

$6.00000000 \mathrm{e}-02$

$5.80000000 \mathrm{e}-01$

$0.00000000 \mathrm{e}+00$

Gambar 8. Titik Pusat Cluster 3

Hasil dari pengelompokkan 3 cluster ditunjukkan dalam gambar 9 .

\begin{tabular}{|c|c|c|c|c|c|c|c|c|c|}
\hline & Nama & Asal_Sekolah & Ipk & KMB ॥ & Kep Jiwa II & Kep Anak II & Kep Maternitas || & KMB IV & Kluster \\
\hline 0 & Adk Aprila Putri Primewati & SMAN & 2.80 & $\theta$ & B & B & 8 & $B$ & $\mathrm{C} 2$ \\
\hline 1 & Amin Nurtidayah Zunita Ferdane & SMAN & 3.29 & $\theta$ & B & B & 8 & $B$ & $\mathrm{C} 2$ \\
\hline 2 & Anom Prihasmoro & SMAN & 283 & B & B & B & B & B & $\mathrm{C} 2$ \\
\hline 3 & Afa Larasat & SMAN & 2.98 & B & B & B & B & B & $\mathrm{C} 2$ \\
\hline 4 & Charul Nine & SMAN & 2.97 & B & B & B & B & 8 & $\mathrm{C} 2$ \\
\hline ... & & & & & ... & $m$ & & & \\
\hline 214 & Kristana & SMKS & 316 & B & B & B & A & A & $\mathrm{Cl}$ \\
\hline 215 & Nur Eka Kurniawan & SMAN & 304 & B & B & B & A & B & $\mathrm{C}_{2}$ \\
\hline 216 & Segtiningrum Nur Cahyati & SMAS & 2.62 & B & B & B & A & B & $\mathrm{Cl}$ \\
\hline 217 & Tnsna Numakim & Pakat C & 3.57 & B & $\mathrm{B}$ & B & A & A & C1 \\
\hline 218 & Ulfan Nur 'Aini & MAN & 3.29 & B & B & $\mathrm{B}$ & A & A & C1 \\
\hline
\end{tabular}

Gambar 9. Tabel hasil clustering

Berdasarkan hasil pengujian purity pada tabel diatas, dapat ditarik kesimpulan bahwa jumlah cluster yang optimal adalah 3. Representasi pengetahuan dari hasil cluster dengan nilai $\mathrm{k}$ adalah 3 sebagai berikut:

1. Cluster 0 mempunyai anggota sebanyak 50, dengan mempunyai rata-rata nilai IPK sebesar 3.26 dan terdiri dari asal sekolah MAN sebanyak 3 siswa, SMAN sebanyak 29 siswa, SMAS sebanyak 2 siswa, SMKN sebanyak 8 siswa, dan SMKS sebanyak 8 siswa. 
2. Cluster 1 mempunyai anggota sebanyak 78, dengan mempunyai rata-rata nilai IPK sebesar 3.05 dan terdiri dari asal sekolah MA sebanyak 2 siswa, MAK sebanyak 1 siswa, MAN sebanyak 17 siswa, Paket C sebanyak 4 siswa, PPKBM sebanyak 1 siswa, SIMK sebanyak 1 siswa, SMAS sebanyak 19 siswa, SMKN sebanyak 15 siswa, SMKS sebanyak 17 siswa, dan SNIK sebanyak 1 siswa.

Cluster 2 mempunyai anggota sebanyak 91 dengan mempunyai rata-rata nilai IPK sebesar 3.08 dan asal sekolah hanya terdiri dari SMAN dengan jumlah siswa 91.

\section{KESIMPULAN}

Dari hasil pengelompokkan diperoleh rekomendasi untuk AKPER KBH bahwa mahasiswa yang berasal dari SMAN, SMKN dan SMKS cenderung memiliki nilai IPK yang cukup bagus, hal ini dapat dibuktikan selisih nilai IPK antara cluster 0 , cluster 1 dan cluster 2 tidak terlalu jauh. Sehingga dari hasil pengelompokkan ini pihak AKPER dapat membuka kesempatan bagi siswa SMAN, SMKN dan SMKS untuk tetap mendaftar sebagai masiswa AKPER KBH.

\section{UCAPAN TERIMA KASIH}

Penelitian ini dapat terlaksana dengan dukungan dari Lembaga Penelitian dan Pengamdian Kepada Masyaarakat Universitas Ahmad Dahlan dalam hibah dana penelitian Dasar Tahun Anggaran 2021/2022

\section{REFERENCES}

[1] N, T. Septioko, H. A. Parhusip, and T. Mahatma, “Aplikasi K-Means Untuk pengelompokkan Rumah tangga di Salatiga berdasarkan Data Susenas 2011," in Pekan Imiah Dosen FEB-UKSW, 2012, pp. 353-372.

[2] G. S. Nugraha, Hairani;, and R. F. P. Ardi, "Aplikasi Pemetaan Kualitas Pendidikan Di Indonesia Menggunakan Metode KMeans," J. MATRIK, vol. 17, no. 2, pp. 13-23, 2018.

[3] M. A. Permatadevi, R. A., M. E. Hendrawan, S.Kom, and M. S. Irmasari Hafidz, S.Kom, "Karakteristik pelanggan telepon kabel menggunakan clustering som dan k-means untuk mengurangi kesalahan klasifikasi pelanggan perusahaan telekomunikasi (studi kasus : pt. Telkom mojokerto)," J. Tek. pomits, vol. 1, no. 1, pp. 1-7, 2013.

[4] L. Zahrotun, N. hutami Putri, and A. N. Khusna, "The Implementation of K-Means Clustering Method in Classifying Undergraduate Thesisi Titles," in 12th International Conference on Telecommunication Systems, Services, and Applications (TSSA), 2018.

[5] L. Zahrotun, "Analisis PengelompokkanJumlah Penumpang Bus Trans Jogja Menggunakan metode Clustering K-Means dan Agglomerative Hierarchical Clustering (AHC)," J. Inform., vol. 9, no. 1, pp. 1039-1047, 2015.

[6] H. Kurnia, L. Zahrotun, and U. Linarti, "InfoTekJar: Jurnal Nasional Informatika dan Pengelompokan Mahasiswa Berdasarkan Data Akademik Sebelum Kuliah dan Masa Studi Menggunakan K-Medoids," J. Nas. Inform. dan Teknol. Jar., vol. 2, no. 2, pp. 265-272, 2021.

[7] B. H. T. Suandi and L. Zahrotun, "PENERAPAN DATA MINING DALAM MENGELOMPOKKAN DATA RIWAYAT AKADEMIK SEBELUM KULIAH DAN DATA KELULUSAN ( Implementation Of Data Mining In Grouping Academic History Data Before Students And Student Graduation Data Using Method Agglomerative Hierarchical Cluste," J. Teknol. Informasi, Komput. dan Apl., vol. 3, no. 1, pp. 62-71, 2021.

[8] J.Han, Kamber.M,.Jian Pie, Data Mining: Concepts and Techniques. 2011.

[9] A. Asroni, H. Fitri, and E. Prasetyo, "Penerapan Metode Clustering dengan Algoritma K-Means pada Pengelompokkan Data Calon Mahasiswa Baru di Universitas Muhammadiyah Yogyakarta (Studi Kasus: Fakultas Kedokteran dan Ilmu Kesehatan, dan Fakultas Ilmu Sosial dan Ilmu Politik),” Semesta Tek., vol. 21, no. 1, pp. 60-64, 2018. 